\title{
Exploration and Research of Accounting Demonstration Experiment
}

\author{
Li-Hong YANG \\ School of Management, Xi'an University of Science and \\ Technology, Xi'an, Shaanxi, China \\ 1506649007@qq.com
}

\begin{abstract}
Reforming the traditional teaching mode of special courses, increasing the teaching of experimental and practical aspects, and building a comprehensive accounting laboratory has become an urgent need for the current teaching reform of accounting courses in colleges and universities. Accounting demonstration experiment has become a major breakthrough to solve this problem. This paper expounds the necessity and opening of the infrastructure, and discusses in detail the ten ways and means of teachers' presentation, and finally discusses the effect of the demonstration experiment in our school.
\end{abstract}

Keywords-demonstration experiment; configuration design; opening effect

\section{INTRODUCTION}

Accounting is a subject with strong practice, experimental teaching plays a very important role in the classroom teaching of colleges and universities in China. At present, there are many problems in the construction of the practical teaching system of accounting in practice, such as the lack of integrity of the system, especially the practice teaching attached to theory teaching, accounting experimental courses offered alone rarely, the system is poor, and mostly manual simulation, tedious and boring. How to compensate for this, become tedious, boring is simple, interesting, and fully mobilize the enthusiasm and initiative of the students and the construction of scientific practice teaching system, college teachers should seriously consider is the problem.

\section{ACCOUNTING Demo LAB CONFIGURATION DESIGN}

Accounting simulation teaching needs to create a good simulation environment, so the layout of the laboratory should pay attention to the scene layout of the environment and more specifically, a comprehensive accounting simulation laboratory that provides the above functions may be equipped with the following hardware and software facilities:

\section{A. Simulation Laboratories with Specialized Applications}

According to the actual layout of the accounting and finance department, each group is equivalent to a financial department, including cashiers, systems, and records. Accounting, cost accounting, general ledger accounting and accounting supervisor and other positions, and configure the manual operation for the paper, accounting stamp,

\author{
Xiao-Tian LIANG \\ School of Management, Xi'an University of Science and \\ Technology, Xi'an, Shaanxi, China \\ 15091677566@163.com
}

private seal, financial dedicated seal, corporate seal, glue, ink box, pencil, ruler, eraser, red and blue pen, clip, file bag, file cabinets and all kinds of original vouchers, accounting vouchers, financial statements and other necessary tools in manual simulation, so that students have a simulation of the real operating environment, to enhance students' perceptual knowledge.

\section{B Configuration 1-2 Servers and Multiple Sites, and the Installation of Accounting Software}

The laboratory can be configured 1-2 servers and multiple sites, the accounting software can be considered a larger market share of the mature commercial software, such as UFIDA, Kingdee, and timely upgrade. If possible, according to the needs of teaching, construction of local area network, and provides the campus network interface, improve the adaptability and application the laboratory experiment, convenient management.

\section{Equipped with Multimedia Teaching System}

The system includes a computer with a teacher, a video demonstration instrument, video recorders, video converter, video switcher, TV and other equipment. Teachers can easily use a variety of teaching media, and timely computer, video recorder, video demonstration instrument, VCD signals transmitted to the TV show to teach good effect.

\section{DEMONSTRATION EXPERIMENT IN ACCOUNTING MANUAL PRACTICE}

The establishment of the demonstration experiment, according to the basic steps of accounting, take the economic business of a company in December as the template, and arrange ten demonstration projects in the link. The concrete implementation steps and contents are as follows:

\section{A Writing Technical Training}

Accounting personnel should master the digital Arabia Chinese characters, standard capital number, make the content accurate, concise and to the point, neat, clear, for the future engaged in accounting work. In this regard, the teachers in the training content to explain in detail, can use the multimedia player personnel engaged in accounting work in the business license, registration account to prepare financial statements etc. in Arabia, how to use digital writing, how to regulate the correction in the registration error, how to do can make writing clear, clean, easily 
identifiable and not easy to be tampered with, to enable students to acquire perceptual knowledge is very important to further seriously grasp the method of the way of writing.

\section{$B$ Fill in the Original Documents and Audit}

The original documents, and documents, is to obtain or fill in business operations or at the completion of the use of economic business proved to record or the completion of the writing. Learn to fill in and check the original documents, is very important for the accounting personnel. Teachers in the demonstration of this item, first find the original documents and fill in audit in case lead enterprises have suffered great economic losses, let the students watch, so the importance of deep understanding of this training content. Then the teacher in accordance with the original documents of meaning, types, basic content, basic required, method of verification and inspection of the original documents, the original documents in the wrong and wrong. Error identification content presentation, gradually to the students to explain, so that students of the original vouchers and review of a more comprehensive and profound understanding. Finally, grouping of students and teachers, to provide the correct original documents and wrong, let each student identification and correction.

\section{Fill in and Audit the Accounting Voucher}

The voucher is used to convert the information into economic accounting information, accounting vouchers for classification of economic business. Master fill in and audit the accounting voucher is become a basic requirement for a qualified accountant. Accounting voucher demonstration by teachers themselves should be filled out manually turn receipt and payment vouchers, in the process, gradually to the students should pay attention to every step, such as: vouchers vouchers should be numbered consecutively; if the error occurs in such problems should be re. Teachers will record the demo video, distributed to students, to prepare students for later understand, finally let the students practice.

\section{Accounting, General Ledger and Subsidiary Ledger Settings and Registration}

According to the accounting vouchers and the attached original documents in chronological order of daily register related journals, general ledger and subsidiary ledger. The teacher demonstrates this part, should be classified as a breakdown, divided into three columns, quantity and amount, type, multi column type, should be classified and described, and production presentation of the document, the content covers how to register, notices, and indicate the impact of false registration of late accounting work, and then play professional video recording process, let the student to the accounts setting and registration of enterprises real, have more intuitive understanding.

\section{E Error Checking and Correction}

The exact distinctions between the wrong account, and can choose the proper method to correct the wrong account, master the correct method of all the wrong account, is particularly important for accounting personnel. This demonstration, teachers should first broadcast related cases does not regulate the wrong account corrections to the enterprise caused heavy losses, then teachers need to make presentations, including: causes of accounting the wrong account, type the wrong account, find the wrong account method, error correction method to correct the wrong account account, matters needing attention, for students to enable students to explain in detail. This content has a more profound understanding, mastering the correct methods of accounting.

\section{F Reconciliation and Settlement}

Ensure the account card, account, accounts, accounting information is correct and reliable, and for the preparation of accounting statements to provide true, reliable data. The understanding of the nature of various accounts, the account balance of different types of clear direction, grasp the various properties of the account settlement method, is a basic requirement for a qualified accounting personnel of this. The content of the presentation, the teacher should personally operation again, during the operation process, to the students of each step should be paid attention to. And in the presentation, showing the correct reconciliation and error checkout, let the students have a more emotional awareness.

\section{G Bank Balance Adjustment Sheet}

The balance of the bank to provide reconciliation of bank deposits and registration of student journals, individually checked accounts. In the process, found the pending accounts, shall prepare bank reconciliation statements, and analyze the reasons for the errors of the teachers. In this part, students should be encouraged to carefully check and found the problem, discussion exchange with your classmates, do not understand ask teacher. The teacher will summarize the problems, and make a presentation, one by one to teach students. The students can grasp the method of bank deposit check, grasp the compiling method of bank balance sheet adjustment.

\section{H Preparation of Accounting Statements}

According to the requirements of the registration ledger, subsidiary ledger books monthly amount and final balance, prepare a balance sheet and income statement. The contents of this demonstration, teachers should take the form of presentations, show students reporting way, and show the completed report style, and then broadcast the accounting statements of the real business process the video, so that students have a certain understanding of financial statements. Finally, students according to their own requirements before doing the accounts, the preparation of the report. And summarize the existing problems in this process, teachers collect these problems, making presentations to students unriddling. 


\section{ACHIEVEMENTS}

Through the implementation of accounting experiment and adopt a variety of comprehensive management measures, in our accounting simulated practice achieved good results. From the beginning of 2014 for the initiative, has been 3 years. Table 1 is the questionnaire statistics over the past four years students in the accounting simulated practice satisfaction, table 2 it is nearly four years students in the accounting simulated practice performance distribution table.

TABLE I STATISTICAL TABLE OF SATISFACTION DEGREE OF UNDERGRADUATE STUDENTS MAJORING IN MANUAL SIMULATION IN 2013--2016

\begin{tabular}{cccc}
\hline year & $\begin{array}{c}\text { Total number of } \\
\text { tests }\end{array}$ & $\begin{array}{c}\text { Test satisfaction } \\
\text { rate }\end{array}$ & $\begin{array}{c}\text { Rate of } \\
\text { unsatisfactory } \\
\text { detection }\end{array}$ \\
\hline 2013 & 112 & $66.96 \%$ & $33.04 \%$ \\
2014 & 120 & $75.83 \%$ & $24.17 \%$ \\
2015 & 125 & $84.00 \%$ & $16.00 \%$ \\
2016 & 156 & $91.67 \%$ & $8.33 \%$ \\
\hline
\end{tabular}

TABLE II DISTRIBUTION OF GRADES OF MANUAL SIMULATED PRACTICE IN 2013--2016

\begin{tabular}{|c|c|c|c|c|c|c|c|}
\hline \multirow{2}{*}{ year } & \multicolumn{2}{|c|}{ excellent } & \multicolumn{3}{|c|}{ secondary } & \multicolumn{2}{|r|}{ good } \\
\hline & \multicolumn{6}{|c|}{ number Proportion number Proportion number } & Proportion \\
\hline 2013 & 12 & $10.71 \%$ & 45 & \multicolumn{2}{|c|}{$40.18 \%$} & 16 & $14.29 \%$ \\
\hline 2014 & 32 & $26.67 \%$ & 26 & \multicolumn{2}{|c|}{$21.67 \%$} & 42 & $35.00 \%$ \\
\hline 2015 & 41 & $32.80 \%$ & 25 & \multicolumn{2}{|c|}{$20.00 \%$} & 45 & $36.00 \%$ \\
\hline 2016 & 62 & $39.74 \%$ & 38 & \multicolumn{2}{|c|}{$24.36 \%$} & 51 & $32.69 \%$ \\
\hline \multirow{2}{*}{ year } & \multicolumn{3}{|c|}{ pass } & \multicolumn{3}{|c|}{ Fail } & \multirow{2}{*}{$\begin{array}{l}\text { Sum up } \\
\text { (person) }\end{array}$} \\
\hline & number & Propor & & \multicolumn{3}{|c|}{ number Proportion } & \\
\hline 2013 & 30 & 26.79 & & 9 & 8.0 & & 112 \\
\hline 2014 & 18 & 15.00 & & 2 & 1.6 & & 120 \\
\hline 2015 & 13 & 10.40 & & 1 & 0.8 & & 125 \\
\hline 2016 & 5 & 3.21 & & 0 & 0 & & 156 \\
\hline
\end{tabular}

From table I and table II we can see that after taking a variety of innovative measures, the students' satisfaction has been improved significantly, and the achievement rate has been steadily increasing, mainly in the following aspects:

(1) The degree of satisfaction of students who participate in manual practice is improved significantly, and the enthusiasm of students to participate in practice is increasing

(2) Can be seen from table 1: 2013 to participate in the survey of the students satisfaction is $66.96 \%$, the 2014 began to implement accounting demonstration experiment, satisfaction reached $75.83 \%$, compared with 2013 growth of $8.87 \%$; 2016 student satisfaction is $91.67 \%$, compared to 2013 increased by $24.71 \%$. before the implementation of the knowledge, enhance students' satisfaction greatly implement the accounting experiment, the practice effect is more obvious.

(3) The outstanding rate of student achievement increases year by year

(4) Table 2 shows, through the accounting experiment teaching, our school students participate in accounting training excellence rate steadily increased, increased from $26.67 \%$ in 2014 to $39.74 \%$. in 2016 these shows that accounting experimental teaching, our school has obvious effect, achieved remarkable results.

\section{ACKNOWLEDGMENT}

This research was financially supported by the China Institute of Degree and Graduate Education Project "Accounting graduate student manual training course set" (2015Y0502)and Xi'an University of Science and Technology project "accounting manual training reform and innovation research" (ZX16066).

\section{REFERENCES}

[1] Li Min. How to use good accounting simulation laboratory $\mathrm{J}$. Northern literature (the second half), 01 (2011)59-60.

[2] Liu Huijuan. Accounting undergraduate education practice teaching problems D. Shanxi University of Finance and Economics, 2011.

[3] He Jianwu, Ma Mingyou, Chen Bin, Zhou Caiyun. Problems and Countermeasures of Open Management of Teaching Laboratories in Local Colleges and Universities [J]. Laboratory Research and Exploration. 04(2014)240-242.

[4] Chen Xiaojing. On the college accounting information experiment teaching reform [J]. Commercial Accounting. 06 (2013)114-116.

[5] Ming Zhe. Accounting professional accounting course teaching reform analysis [J]. Hebei enterprises. 12(2016)213-214. 